\title{
Diferentes olhares sobre a natureza - representação social como instrumento para educação ambiental
}

\author{
Lúcia Maria Alves e Silva \\ Edvânia Torres Aguiar Gomes \\ Maria de Fátima de Souza Santos \\ Universidade Federal de Pernambuco
}

\begin{abstract}
Resumo
O presente trabalho representa um esforço de identificação do significado de natureza por diferentes grupos sociais que atuam nas praias de Gamela e Guadalupe, litoral Sul de Pernambuco. Como referência teórica, tomou-se a abordagem das representações sociais de Moscovici, a abordagem estrutural de Abric e a perspectiva societal de Doise. A obtenção e análise dos dados seguiram uma orientação pluri-metodológica revelando, por um lado, a existência de um campo comum das representações orientado pela idéia de natureza provedora, fonte de vida, frente à necessidade da preservação. Por outro, as diferenciações grupais revelaram uma natureza provedora das necessidades humanas tanto no sentido físico como no sensual. A presença de representações hegemônicas demarca uma crise que confirma o espaço relacional sociedade humana-natureza em processo de transformação na busca de novas configurações. Este trabalho ratifica a importância da utilização da teoria das representações sociais como um instrumento teórico e metodológico para o conhecimento das representações sociais de natureza.
\end{abstract}

Palavras-chave: representação social; educação ambiental; gestão ambiental; natureza

\begin{abstract}
Different looks on nature - social representation as a tool for environmental education. The present report represents an effort towards the identification of the meaning of nature for different social groups present in the beaches of Gamela and Guadalupe, on the Southern coast of Pernambuco. As its theoretical references, the article embraces Moscovici's theory of social representations, Abric's structural approach and Doise's societal perspective. Data collection and analysis followed a multi-methodological orientation, disclosing the existence of a common field of representations guided by the idea of the nature as source of life, linked to the necessity of environmental preservation. On the other hand, the group's differentiation showed nature as supplier, both in the physical and the sensual direction, related to human beings necessities. The presence of hegemonic representations makes explicit a crisis that confirms the relational space human society-nature in process of transformation in search of new configurations. This study ratifies the importance of the use of social representations theory as a theoretical and methodological instrument aimed at the knowledge of social representations of nature.
\end{abstract}

Keywords: social representations; environmental education; environmental management; nature

$\mathrm{U}$ m breve resgate na história das discussões, debates e eventos locais e internacionais em torno da problemática ambiental nas últimas três décadas revela a necessidade de integração e participação de todas as áreas de conhecimento - até mesmo do senso comum - e de todos os setores sociais, nas intervenções ambientais. Envolvendo do planejamento à execução, com vistas ao estabelecimento de uma Gestão Ambiental (GA) comprometida.

Entre as dificuldades para uma GA comprometida com a qualidade do ambiente, está a capacidade de implementar uma gestão participativa integrando todos os grupos sociais
(GS) que atuam em um determinado empreendimento, empresa, unidade de conservação, município, etc. Um dos desafios, nesse sentido, é traduzir e conhecer informações de uma área e de outra: técnica/técnica, técnica/popular e popular/técnica. É necessário transparência dos valores e interesses subjacentes a cada posição. É preciso evitar a manipulação, por grupos dominantes, dos grupos historicamente menos favorecidos.

A preocupação deste trabalho é com o conhecimento do senso comum, sua dinâmica de produção e inserção social nas relações que vão definindo o ambiente a partir da interação dos diferentes GS em situações ambientais concretas. 
Partindo-se do pressuposto de que na base da problemática ambiental está a relação homem-natureza, sociedade humana-natureza, supõe-se que o estudo das representações sociais de natureza ${ }^{1}$ (RSN) apresenta-se como um fértil campo para a aquisição de conhecimento, interpretação e reflexão dos diferentes olhares, valores, interesses, posições e práticas que circulam entre os GS acerca desse objeto. A representação social (RS) é definida por Moscovici (1978) como "um corpus organizado de conhecimento e uma das atividades psíquicas graças a qual os homens tornam inteligível a realidade física e social, inserem-se num grupo ou numa ligação cotidiana de trocas, e liberam os poderes de sua imaginação” (p. 91).

A teoria das Representações Sociais (TRS) é apresentada na perspectiva da apreensão dos conteúdos de composição e dos processos de formação das representações e define, segundo Moscovici (1978, p. 174), uma instância no domínio do ser e outra no domínio do fazer. Para ele (Moscovici, 1978, p. 77), uma representação é social na medida em que contribui para os processos de formação de condutas e de orientação das comunicações sociais. Referências às quais Abric (1998) faz eco, destacando a importância da função das RS como um sistema de interpretação e intervenção no meio físico e social. Assim sendo, a TRS apresenta-se como um referencial teórico e instrumento para a educação e a gestão ambientais, na identificação dos conhecimentos e das práticas sociais que se articulam no espaço relacional sociedade humana-natureza.

A partir dessa orientação, este trabalho busca analisar as atuais RSN, de alguns dos diferentes Grupos Sociais ${ }^{2}$ que atuam nas áreas das praias de Gamela e Guadalupe, localizadas no município de Sirinhaém, no litoral sul de Pernambuco.

Esta abordagem visa compreender: os sistemas de significação socialmente construídos e compartilhados dos grupos com atuação direta na área acerca da natureza; a presença de idéias e valores que marcam o desenvolvimento do pensamento ocidental nas atuais RSN analisadas e a interface dessas representações com os comportamentos e práticas atuais na relação sociedade-natureza locais. A perspectiva é de que essas informações abram espaço para a compreensão das interações que estão se estabelecendo, entre os grupos envolvidos, para a criação e recriação do ambiente local.

A área selecionada para a pesquisa possui algumas características fundamentais para o foco de interesse desta proposta. Primeiro, pela diversidade de atores sociais que se organizam em grupos distintos (moradores, veranistas e turistas). Segundo, porque, por um lado, é parte de um centro turístico, o CT-Guadalupe, foco da atual dinâmica de desenvolvimento econômico do litoral sul de Pernambuco; e, por outro, pertence, assim como as outras praias do centro turístico e demais áreas de seu entorno, a uma unidade de conservação da natureza, a Área de Proteção Ambiental (APA) de Guadalupe. Essas duas condições são já suficientes para fazer emergir uma riqueza de imagens, idéias, valores, interesses e conflitos que permeiam as RSN desses atores sociais.

O processo de criação e implantação do CT-Guadalupe e da APA de Guadalupe é carente de estudos e informações sobre a dinâmica sócio-cultural dos grupos da área. Os estu- dos que existem são de categorização e identificação de atividades produtivas e ocupações habitacionais (Companhia Pernambucana do Meio Ambiente, 1998). A ausência de informações sobre a dinâmica sócio-cultural dificulta qualquer trabalho de gestão e educação ambiental (EA), uma vez que trabalhar com GA é articular em sua abordagem teórica e prática uma ação mediadora de interesses e conflitos dos grupos que realizam determinadas atividades e ocupam espaços precisos a partir de interesses diversos.

Na prática, observa-se que a participação e envolvimento desses atores sociais com os seus problemas ambientais estão diretamente relacionados às diferentes RS que eles têm de natureza. No entanto, um breve olhar histórico mostra que, apesar das diferenças que se estabelecem entre as RS de diferentes grupos da sociedade em uma mesma época, elas são marcadas pela identidade de alguns valores e idéias (ideologias) que quase sempre são manipuladas em favor dos interesses dos setores dominantes. O estudo dessas representações da natureza é um caminho escolhido para ampliação dos conhecimentos sobre a dinâmica sócio-ecológica local e deverá contribuir, em um primeiro momento, para uma reflexão crítica acerca das relações que se estabelecem nessa dinâmica. Poderá ainda fornecer subsídios para a identificação de estratégias e táticas a serem utilizadas pelos segmentos locais, na defesa de seus direitos a uma melhor qualidade de vida e para uma prática educativa e gestora mais comprometida com o equilíbrio do ambiente.

\section{Representação social de natureza - um enfoque teórico e metodológico}

A TRS será, assim, o referencial teórico que orientará este trabalho na direção de um estudo comparativo entre diferentes GS (moradores, turistas e veranistas). A expectativa é de que o conhecimento dos conteúdos, das estruturas e dos processos de construção das RS desses grupos permita identificar, não apenas as diferenças de representações que se supõe existir sobre a natureza, mas também as idéias e os valores que possam ser comuns aos três grupos e que, num jogo de interações entre eles, possam estar definindo identidades, posições e orientando as condutas e as práticas sociais que contribuem para a construção e reconstrução da realidade ambiental.

\section{Modelo teórico e metodológico de análise}

Para este estudo, foi utilizado um modelo de análise quantitativa das RS, que toma por base um quadro teórico e metodológico exposto por Doise (2000). Com base na teoria das RS, Doise (2000) propõe a construção de uma psicologia societal, que imbrica o estudo dos sistemas cognitivos no plano individual com os estudos dos sistemas relacionais e societais. Para ele, a perspectiva de estudo das RS proposta por Moscovici exige uma abordagem relacional dos sistemas cognitivos complexos do indivíduo com os metasistemas de relações simbólicas que caracterizam uma sociedade.

$\mathrm{Na}$ perspectiva de uma psicologia societal, os estudos das RS devem, então, integrar em suas explicações hipóteses 
sobre os modos de funcionamento social e individual. O modelo proposto trabalha em três diferentes fases de análise, articulando regulações societais e modos de funcionamentos cognitivos. Nessa perspectiva, Doise defende a idéia de que todo estudo de RS impõe o estudo comparativo dos grupos sociais, sob pena de perda da dimensão societal (posicional e ideológica) das RS.

As hipóteses de base destas fases de análise estão expostas em Doise (2000). A primeira parte da posição de que diferentes membros de uma população (membros de diferentes GS) compartilham crenças comuns próprias a uma dada relação social, uma vez que as RS se originam em um espaço relacional de comunicações, que pressupõem referências comuns aos indivíduos ou grupos implicados nas trocas simbólicas (o campo comum das RS). A segunda hipótese focaliza a natureza das posições individuais em relação a este campo de RS. Aqui, a TRS vai explicar o como e o porquê os indivíduos ou GS se diferenciam nas relações que eles estabelecem com essas representações. A terceira propõe considerar a ancoragem das tomadas de posições em outras realidades simbólicas coletivas, com foco em: hierarquia de valores, percepções das relações entre grupos e categorias e experiências sociais compartilhadas.

Como apoio a este modelo de análise utilizou-se o referencial teórico e metodológico da estrutura das RS proposto por Abric (1998). Para esse autor, as RS são formadas por dois componentes organizados: o núcleo central e o sistema periférico. O núcleo central é o elemento fundamental da representação uma vez que é ele quem determina seu significado e sua organização interna. Sua propriedade principal é a estabilidade, isto é, ele é formado pelos elementos mais estáveis da RS, aqueles que mais resistem à mudança.

Os elementos do sistema periférico, por sua vez, são estruturados em torno do núcleo central e estão, portanto, em relação direta com ele. Têm um papel essencial no funcionamento e na dinâmica das RS, sobretudo face à realidade das práticas relativas ao objeto. Enquanto o núcleo central é a parte mais "dura" das RS, o sistema periférico é exatamente a parte mais leve, mais maleável delas. Os elementos periféricos são um complemento indispensável do sistema central, do qual dependem. Graças a esses elementos, as RS podem se ancorar na realidade imediata. Eles permitem as modulações individuais das RS, isto é, as variações pessoais, sem pôr em questionamento os elementos do núcleo central. Neste sentido, eles intervêm nos processos de defesa das RS, integrando novas informações sem que o núcleo central seja modificado ou sequer atingido.

A partir desta orientação, três fases de análises foram então realizadas. A primeira fase buscou identificar os elementos que constituem o campo comum das RSN (sua estrutura e seu conteúdo), os elementos que são comuns a indivíduos dos grupos pesquisados (turistas, veranistas e moradores). A segunda fase procurou não apenas a tomada de posição individual, mas a tomada de posição dos diferentes GS pesquisados. Finalmente, a terceira fase visava à análise da ancoragem das RS de cada grupo pesquisado no contexto relacional desses grupos, de suas realidades simbólicas coletivas.

\section{Os participantes pesquisados e as técnicas de coleta e análise dos dados}

Foram envolvidos neste estudo 236 participantes que interagem nas praias de Gamela e Guadalupe. Essas pessoas foram divididas em três grupos, em função de uma única variável: o tipo de vínculo que estabeleciam com a natureza local. De acordo com a abordagem estrutural (Abric, 1998), a proximidade ou distanciamento do grupo com relação ao objeto tem influência nas RS por eles elaboradas. Assim, o grupo de moradores tem vínculo próximo, permanente e cotidiano com a natureza local; os turistas, por sua vez, têm um vínculo flutuante, ocasional com o lugar; e, por fim, os veranistas estabelecem um vínculo intermediário, na medida em que utilizam com freqüência o local como espaço de férias e lazer, sem, no entanto, vivê-lo cotidianamente. No que se refere à faixa etária, houve certa variação. Os turistas e veranistas tinham idade entre 21 a 45 anos. A decisão de trabalhar também com os moradores idosos (fora da faixa previamente definida como adulto) foi tomada no início das entrevistas. Ela foi motivada pela presença marcante de duas gerações bem definidas nas residências, o que implicou uma oportunidade para enriquecimento da pesquisa, tanto pela possibilidade de comparação das duas faixas etárias, como pela vivência dos moradores idosos com um passado de preservação da área, quando a mata de restinga ia até a beira mar.

Para coleta e tratamento dos dados optou-se por uma abordagem pluri-metodológica, que tem como ótica atender aos objetivos propostos no presente estudo, utilizando técnicas já testadas pela teoria TRS. Assim, foram utilizadas duas técnicas de coleta: a associação livre (cujo termo indutor era natureza) e uma entrevista semi-estruturada. Os dados foram analisados com o apoio dos softwares EVOC e ALCESTE, possibilitando a análise da estrutura da RS, tal como proposto por Abric (1998), e uma análise relacional, considerando os modos de funcionamento social e individual, na perspectiva proposta por Doise (2000).

A partir da orientação para verificar o campo comum das RSN, elaboradas no espaço relacional de moradores, turistas e veranistas nas praias de Gamela e Guadalupe, os dados coletados foram submetidos, com o apoio do software EVOC, a dois níveis de análise: análise de evocação e análise de palavra principal; buscando a identificação da organização estrutural do campo comum dessas representações pesquisadas.

Análise de evocação: este primeiro nível de análise identificou os elementos centrais hipotéticos das RS. O cruzamento entre freqüência de emissão e ordem de evocação utilizadas pelos participantes em suas respostas foi o critério definidor da relevância dos elementos em relação ao termo indutor, revelando a organização interna das representações.

Análise de palavras principais: esta análise fez um cruzamento entre os resultados da análise de evocação com a análise das palavras indicadas pelos participantes como as mais importantes. Este é um procedimento que visa a testar a centralidade dos elementos evocados. 


\section{Resultados e discussão}

De acordo com os referenciais teóricos e metodológicos, os resultados e as discussões estão apresentados em três fases de análise.

\section{Fase 1: o campo comum das representações sociais de natureza}

A estrutura das representações sociais. Uma comparação entre os resultados da análise de evocação e da análise de palavra principal apresentou os elementos mar e vida como centrais da RS, por se confirmarem nos dois níveis de análises. Eles são, então, os elementos estruturantes na definição de significados e organização do campo comum das RSN dos moradores, veranistas e turistas que interagem em Gamela e Guadalupe. Outros elementos, como: plantas, sol, preservação e mangue, tanto por suas altas freqüências como por se confirmarem como elementos da periferia no momento da análise da palavra principal, têm também alta probabilidade de comporem a dinâmica central dessas representações. Eles estão, porém, numa periferia próxima do núcleo da representação, assegurando um espaço relacional, como mediação das intervenções no social e das possibilidades de transformações das representações.

Desta forma, os elementos mar e vida, enquanto estruturantes da representação, vão confirmando o sentido e significado de natureza enquanto provedora, enquanto fonte de vida. Eles são os elementos mais estáveis da representação, determinam valores e regras sociais que definem sentidos e significados, geram condutas e regem comportamentos. Nesta ótica, o elemento preservação, por sua alta freqüência e por se confirmar nas duas análises (ainda que, em uma, na periferia próxima) parece estar influenciando a organização da representação, numa perspectiva mais central, incorporando-lhe o sentido da necessidade de preservação da natureza, enquanto regra, enquanto lei. Estes sentidos associam-se a elementos de caráter mais funcionais, quase sempre na periferia da representação. Um espaço de mudança entre o velho e o novo e de mediação entre o interno (individual) e o externo (campo social), mas também e principalmente de ação e de prática social, aqui representado pelos elementos plantas, água, mangue, sol, como os elementos de mais altas freqüências entre os periféricos e, portanto, mais representativos da prática social desses participantes.

Uma melhor compreensão e visualização destes sentidos e significados são reveladas a partir de uma aproximação do contexto semântico de inserção desses elementos: mar, vida e preservação, nas respostas dos participantes à entrevista semi-estruturada, analisada com o apoio do software ALCESTE.

Os conteúdos das representações sociais de natureza. A análise das entrevistas semi-estruturadas foi o percurso utilizado para a apreensão dos sentidos e significados que dão suporte ao campo comum das RSN. Partiu-se de uma análise textual das produções semânticas dos participantes, visando a identificar as informações essenciais do texto, através do ALCESTE, com o objetivo de identificar o conteúdo compartilhado nas relações sociais que se estabelecem entre os grupos pesquisados. Esta análise revelou a existência de seis classes de palavras, inter-relacionadas (Figura 1).

As palavras que compõem cada classe foram selecionadas tomando-se como referência a freqüência, o percentual de cada uma delas para sua respectiva classe e o seu grau de significância ${ }^{3}$. Além disso, foi dispensada especial atenção ao contexto em que as classes de palavras estão inseridas na busca do acesso ao contexto semântico como elemento indicador de RS.

Como resultado da análise dois eixos de organização, que se estabelecem entre as classes, foram revelados a partir da força de associação entre as classes, definida em R. Um eixo, formado pelas classes 1, 2, 6 e 5, apresenta quatro classes em diferentes graus de associação, que definem em seu conjunto uma preocupação ambiental. Este enfoque articula duas classes, a 2 e a 6, que apresentam uma forte associação ( $r=0,67)$, em torno da preocupação política e de cuidado com a natureza, e juntas, se relacionam num grau mediano ( $r=$ 0,50 ), com a classe 5 , que encerra um sentido de expectativa. Estas por sua vez se conectam com a classe 1 por um grau de associação bem mais moderado $(r=0,30)$, que denota um sentido do que era a natureza no passado. O outro eixo articula as classes 3 e 4 fortemente associadas $(r=0,70)$, e juntas, definem um sentido de lugar ${ }^{4}$ cotidiano.

O primeiro eixo refere-se ao sentido de preocupação ambiental dos participantes, em função da introdução das atividades turísticas. Ele está organizado em torno da relação entre um "passado” (classe 1) nostálgico, de uma natureza outrora provedora (tinha, era, mudou, antes, fartura), diante das "expectativas" (classe 5) com o futuro da utilização da natureza (emprego, vai, bom, ruim, hotéis, destruir, piorar), revelando um forte sentido de "preocupação com a natureza" (classe 6) (lixo, jogo, praias, educação, campanha, cuidado, preservar), e da "preocupação política” (classe 2) (interesse, econômico, participativo).

Já o segundo eixo articula em sua organização um sentido forte de lugar cotidiano, que denota uma posição de apego aos recursos da natureza local, indicando uma resistência em relação à introdução do turismo na área. Ele articula, na classe 3, o discurso do veranista com o sentido da importância da preservação da natureza local, enquanto qualidade de vida, numa perspectiva do lugar cotidiano. O contexto é de preservar a natureza que é "nossa" (natureza, homem, nossa, fundamental, preservação, precisamos, somos, sobrevivemos). Na outra classe (4), o discurso é típico do morador, e denota um sentido de fonte de vida, também marcado pela conotação do lugar cotidiano. A natureza, enquanto aquele lugar deles, com o qual eles estabeleceram vínculos, onde nasceram, cresceram, viveram e se alimentaram (nossa, desde que nasci, vivi, cresci, alimentação, beira mar, Gamela, Guadalupe).

\section{Fase 2: as peculiaridades grupais frente à representação social de natureza}

Esta fase da análise possibilitou a identificação das peculiaridades grupais, das diferenças entre as RSN dos moradores (subgrupo A e B), veranistas e turistas. 


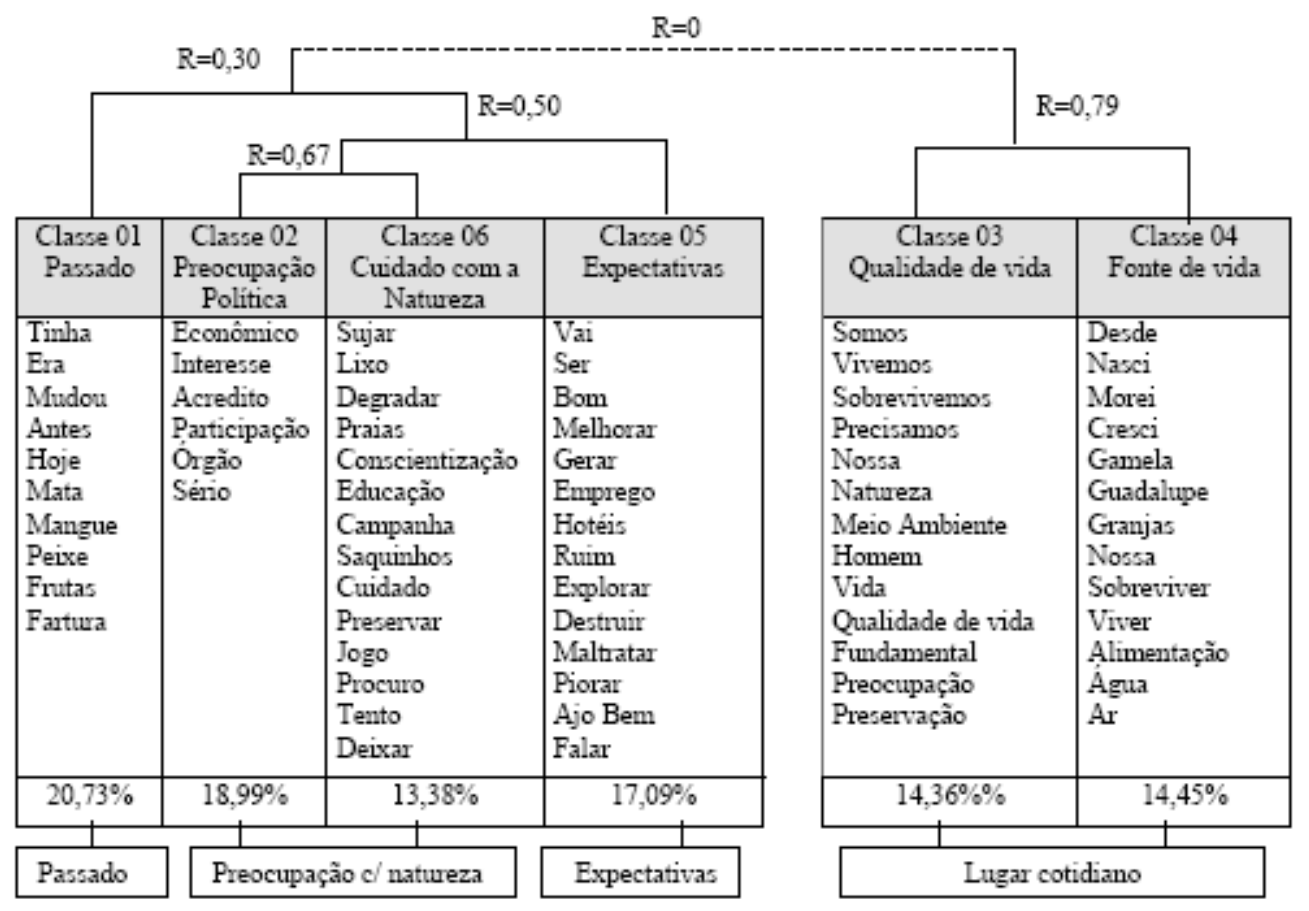

Figura 1. Estrutura do corpus de dados dos participantes, obtida na entrevista semi-estruturada, sobre suas relações com a natureza, organizado em 6 classes (testes de $\chi^{2}$ em cada classe e percentagem de cada classe em relação ao todo, $\mathrm{N}=236$ ).

Como na Fase 1, dois procedimentos de análise fora desenvolvidos: (1) análise fatorial de correspondência, que permitiu a visualização das oposições resultantes da classificação hierárquica descendente a partir da análise textual dos conteúdos da entrevista semi-estruturada, realizada com o apoio do ALCESTE; (2) análise da estrutura das RS de cada um dos grupos estudados que, a partir das referências utilizadas e do modelo já aplicado vai realizar, com o apoio do EVOC, a análise de evocação e de palavra principal.

Oposições resultantes. Um plano fatorial, resultado da análise fatorial de correspondência do ALCESTE permitiu em função da classificação hierárquica descendente visualizar as posições discursivas opostas, produzindo variáveis suplementares traduzidas do discurso das seis classes examinadas na fase anterior. Observa-se que o discurso dos participantes fica exposto em diferentes zonas que tem uma correspondência direta com o conteúdo específico de cada classe.

A projeção de um plano fatorial (Figura 2) apresentou as palavras analisadas no cruzamento entre os fatores 1 e 2, projetando as variáveis suplementares (nível sócio-econômico, vínculo com o local) e as classes resultantes da análise de conteúdo.

O resultado da análise apresenta as oposições resultantes que se revelam por um lado, nas tensões do nível sócioeconômico (favorecido X desfavorecido) e do vínculo com o local (permanente $\mathrm{X}$ flutuante); e, por outro, nas tensões das posições frente à introdução do turismo no lugar (resistência
X flexibilidade). Uma análise que permite visualizar no plano fatorial de projeção dos dois fatores duas posições, ao mesmo tempo convergentes e divergentes entre si, acerca da natureza.

A natureza como objeto de preocupação a partir de um olhar no passado. Uma natureza que foi fonte de alimento, de saúde, de trabalho, de recursos naturais, de vida, encontra nos moradores de Gamela e Guadalupe (classe desfavorecida com vínculo permanente), um sentido de nostalgia com a saudade de um tempo de fartura e de preocupação com um futuro de escassez. Um discurso que, diante da possibilidade de introdução do turismo, oscila entre uma posição de flexibilidade e outra de resistência para o desenvolvimento, que no momento está representado pelo turismo.

A natureza como objeto de preocupação a partir da proposta de criação do pólo turístico de Guadalupe. Uma posição presente no discurso dos veranistas, turistas (classe favorecida e com vínculo flutuante na área) e de alguns moradores, que chamam a atenção para a necessidade de preservação, de seriedade dos setores sociais e da conscientização e educação para os usuários na relação com a natureza. Um discurso que também oscila de uma posição de resistência a uma posição de flexibilidade diante da introdução do turismo. Na perspectiva da resistência, o discurso de uma parcela dos veranistas é de preocupação com a necessidade de preservação, de conscientização, associado à condição indispensável de preservação da natureza enquanto fonte de vida, para eles próprios (descanso, lazer) e para os moradores (sobrevi- 


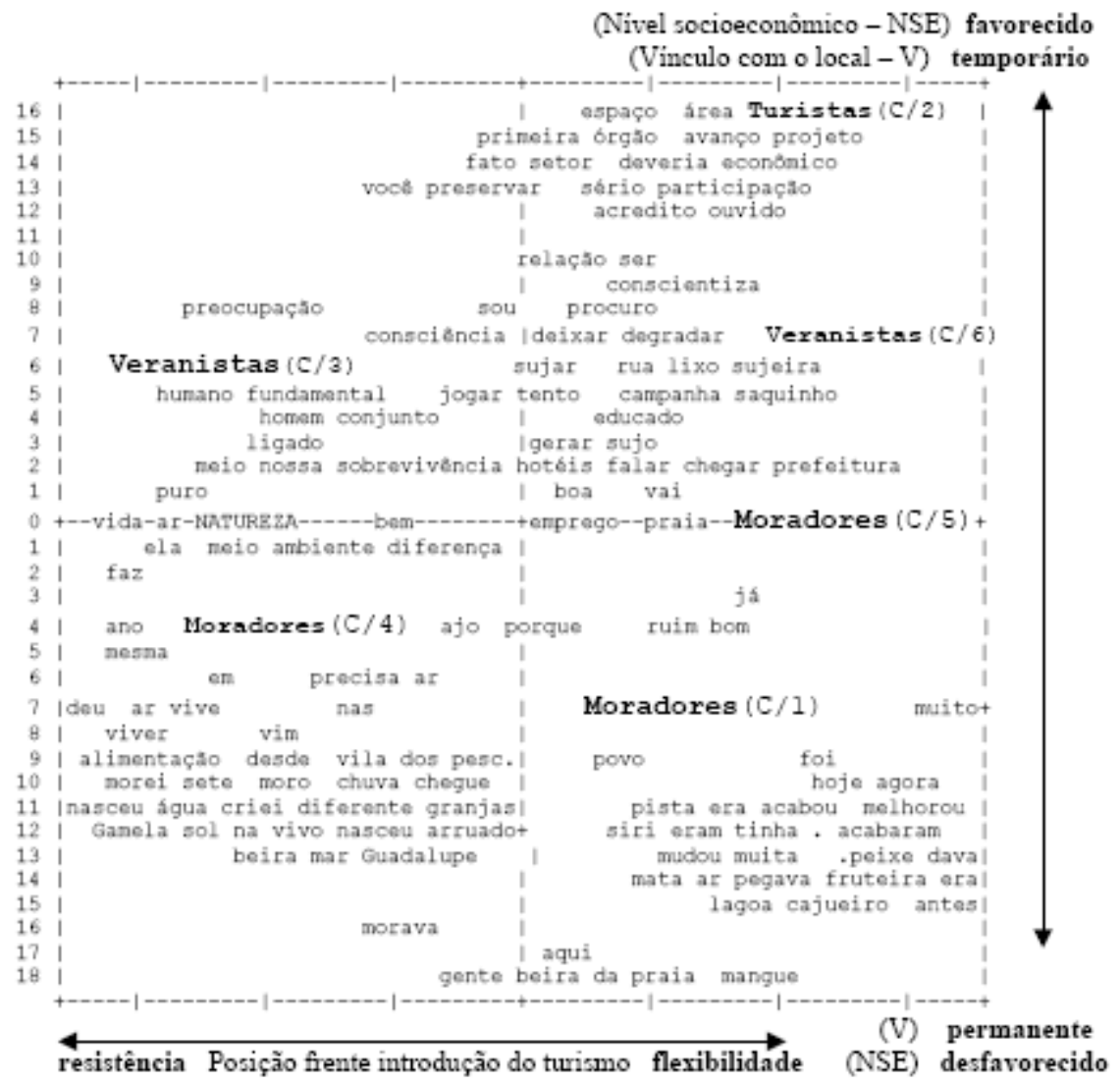

Figura 2. Projeção das palavras analisadas a partir da concepção de natureza dos participantes e das variáveis suplementares: NSE, vínculo com o local e posição frente ao turismo (cruzamento entre os fatores 1 e 2).

vência). A perspectiva de flexibilidade aparece no discurso do turista, de parte dos veranistas e dos moradores. Este é um discurso de flexibilidade, mas também de extrema preocupação com a preservação da natureza, o que aponta para necessidade imperiosa de um processo de conscientização, educação e da realização de campanhas educativas. Esse discurso apresenta também uma perspectiva política de preocupação com a natureza. Ele destaca a possibilidade de dominação econômica, política e intelectual frente à fragilidade da organização social e do nível de educação e consciência da comunidade, como fatores importantes na direção de um modelo de sociedade que deve priorizar a preservação da natureza.

A estrutura das representações sociais dos diferentes grupos sociais. A análise da estrutura das RS, dos diferentes GS estudados, buscou identificar as diferentes posições que caracterizam estes grupos em relação à RSN, definindo assim os elementos do processo de objetivação dessas RS. Ela foi realizada, como já mencionado, em dois níveis de análise; nos moldes utilizados para análise da estrutura da representação do campo comum aos grupos e considerou, numa perspectiva de aprofundamento, os resultados já obtidos na análise fatorial de correspondência.
Conforme os resultados obtidos, os moradores destacam uma natureza provedora, na dimensão física, que se encontra objetivada nos recursos naturais locais: o mangue, o mar, os animais do mangue e do mar, as árvores, as plantas, as frutas nativas, o coqueiro. A dimensão espiritual é presença marcante no contexto semântico, objetivada em Deus como o criador da natureza, o lado sensual (enquanto o sentido, a sensação de prazer de estar ou de contemplar a natureza) aqui aparece apenas como modulações individuais. O vínculo com a natureza está estabelecido a partir de suas práticas sociais na luta pela sobrevivência, que faz utilização direta dos recursos do lugar para a reprodução de suas vidas. A percepção é da dimensão de utilização prática da natureza, através de referências funcionais como pescar, plantar, se alimentar, trabalhar.

No que concerne ao apelo da responsabilidade para com a natureza parece começar a emergir uma referência mais normativa. Estes participantes trazem para o contexto semântico muitas ilustrações de destruição da natureza local. Os depoimentos são sempre na direção de que antes a natureza era mais rica, tinha de tudo com fartura, uma evidência de que o homem está destruindo a natureza. Um contexto de onde 
emerge a cobrança da responsabilidade, no sentido do apelo de que é preciso, de que se deve cuidar da natureza; de que não se pode deixar destruir mais a natureza.

Os outros participantes, veranistas e turistas, destacam a mesma concepção de base dos dois primeiros grupos de moradores, mas, como mencionado anteriormente, com algumas diferenciações. Na concepção da natureza enquanto fonte de vida, a ênfase vai além da dimensão física e espiritual; eles trazem o lado sensual da relação homem-natureza. Outra diferença está no plano da objetivação. Estes participantes utilizam em sua expressão para dar sentidos e significados às suas concepções da natureza, elementos que são cada vez mais genéricos (termos que se distanciam dos elementos naturais existentes no lugar), mais distantes de uma relação concreta de vida e de subsistência com os recursos naturais locais, tanto no contexto da análise da estrutura, como do conteúdo semântico. Os elementos destacados revelam outro tipo de vínculo, na relação com o lugar, expressos em termos como: sol, mar, coqueiro, mangue, peixe, frutas, árvores, animais, beleza, paz, lazer, preservação (veranistas) e vida, mar, árvore, planta, alimento, água, sol, beleza, paz, lazer, preservação (turistas). Como se vê, o segundo grupo ainda mais do que o primeiro.

Uma diferenciação que se estende também para a dimensão estrutural da análise. Diferente dos primeiros, estes dois grupos, veranistas e turistas, já colocam na estrutura da RS a concepção da preocupação com a degradação da natureza. Este sentido, no caso dos moradores, só aparece ao se analisar o contexto semântico do discurso. Com uma diferença também no que se refere à perspectiva da objetivação. Para os moradores, a idéia de natureza é objetivada em termos como destruir e cuidar. Os outros participantes, veranistas e turistas, além de abordarem esta dimensão da responsabilidade e da preocupação com a natureza já no contexto estrutural, objetivam a natureza em termos como degradar e preservar. Ao analisar esses elementos em seu contexto semântico, observa-se que o sentido a eles atribuídos distancia-se do sentido atribuído pelas ciências ambientais, especialmente quando se refere ao termo preservação. Eles apresentam, então, o mesmo sentido e significado de destruir e cuidar usado pelos dois primeiros grupos, com a mesma carga normativa, de que é preciso, de que se deve cuidar da natureza, de que ela não deve ser destruída.

Uma aproximação, agora na direção da comparação entre veranistas e turistas, vai ainda apontar para uma diferença que já se revela na abordagem estrutural. A concepção da preocupação com a degradação ambiental aparece como mais central para os veranistas, representada pelo elemento preservação, enquanto os turistas têm sua maior preocupação na dimensão estética e sensual da natureza provedora. Essa é a preocupação com o seu lazer, trazendo para a centralidade da representação os termos mar, vida, beleza, paz. Diferente dos veranistas, que centram sua grande preocupação na degradação da natureza local. Como os moradores, eles têm uma percepção aguçada de que a natureza local está sendo destruída. Neste sentido, os veranistas apresentam uma posição de mediação entre os moradores e os turistas. Eles, como os moradores, também destacam a destruição da natureza local a partir de ilustrações concretas. Isto é obvio pelo tempo e tipo de vínculo que estabelecem com o local. Quanto aos termos utilizados, a relação mais forte, como já abordado, é com os elementos apresentados pelos turistas, se diferenciando apenas em relação à posição de centralidade ou periferia em que estes termos têm destaque na representação.

Este sentido de preocupação, de responsabilidade e de imposição na direção da proteção da natureza está expresso na necessidade de instalação de um processo de educação para o desenvolvimento de uma consciência crítica na direção da preservação da natureza, tanto para os veranistas, como para os turistas. Ele é, no entanto, uma concepção muito mais forte para os primeiros, evidência de sua preocupação com a destruição da natureza local, seu lugar, seu refúgio de beleza, tranqüilidade e paz.

Uma concepção que se apresenta com menos força para os moradores, os quais destacam na concepção de natureza provedora o sentido de sua sobrevivência. Posição que denota a flexibilidade destes participantes por um espaço de negociação entre a perda de um pouco mais da natureza, que já não é mais tão provedora e o ganho de uma nova opção de sobrevivência e até de melhoria das condições de vida local, representada pela implantação do pólo turístico. Opção, através da qual este grupo vai negociar também as suas identidades, individuais e coletivas.

\section{Fase 3: a ancoragem das representações sociais de natureza}

O estudo da ancoragem das RSN dos moradores, turistas e veranistas teve como referência a articulação entre as RS de cada grupo pesquisado no quadro estrutural dos resultados obtidos nas várias análises realizadas e os elementos identificados no campo comum aos grupos (Figura 3). Na análise foi considerado, também, o sentido dado pelos participantes a cada palavra no contexto do discurso.

No que concerne aos resultados, o estudo revelou que os moradores, turistas e veranistas partilham, como ponto de ancoragem, duas concepções de natureza: a natureza provedora e a natureza degradada ou em processo de degradação, como referências para suas práticas sociais. Na primeira concepção, a natureza comparece enquanto provedora das necessidades humanas (fonte de sobrevivência, fonte de vida, fonte de desfrute estético e sensual); a natureza para o ser humano, para suprir suas necessidades. Essa é uma concepção que se projeta em dois sentidos: a natureza para suprir as necessidades fisiológicas, com destaque para a alimentação e o trabalho; e a natureza para suprir as necessidades do espírito e/ou da sensualidade humana, destacando a paz, a estética, o prazer. É uma concepção que destaca, ou não, a presença de Deus como ser responsável pela criação da natureza, para os seres humanos.

Esta orientação está ancorada na concepção de que a natureza existe para bem servir a humanidade. Na concepção destes participantes está uma concepção já revisitada por muitos (Passmore, 1995; Thomas, 1989; entre outros) no decorrer da evolução da sociedade humana. Uma concepção 


\begin{tabular}{|c|c|}
\hline Morador $(A)(67)$ & Morador (A) (B) (52) \\
\hline $\begin{array}{l}\text { pessoa boa animais domésticos aves tudo } \\
\text { passarinho animais do mar coqueiro sol } \\
\text { mata animais do mangue mangue mar } \\
\text { fruteiras frutas mativas árvore planta }\end{array}$ & $\begin{array}{l}\text { vida passarinho sol terra animais boa } \\
\text { animais do mangue animais do mar pesca } \\
\text { mar mangue coqueiros mata } \\
\text { planta árvore frutas nativa água }\end{array}$ \\
\hline \multicolumn{2}{|c|}{ Vida Mar } \\
\hline $\begin{array}{l}\text { beleza espiritualidade paz preservação vida } \\
\text { ávore plantas coqueiro sol mar } \\
\text { ambiente animais peixe harmonia } \\
\text { sobrevivência lazer praia limpeza } \\
\text { Deus pessoa saúde céu degradação }\end{array}$ & $\begin{array}{l}\text { vida beleza mar sol praia lazer } \\
\text { Deus paz saúde preservação limpeza } \\
\text { harmonia água ávore tudo } \\
\text { ambiente alimento ar puro pessoa }\end{array}$ \\
\hline \multicolumn{2}{|l|}{ Veranistas (75) } \\
\hline
\end{tabular}

Figura 3. Esquema síntese dos prováveis elementos centrais e periféricos das RS da natureza dos grupos sociais pesquisados em Gamela e Guadalupe.

que foi priorizada e destacada, entre outras, como guia para o pensamento oficial ocidental nos dois últimos milênios e que terminou por influenciar fortemente os rumos da relação sociedade-natureza no mundo ocidental.

A segunda concepção da natureza que permeia o campo comum das RS é também marcante para moradores, veranistas e turistas: a natureza degradada ou em processo de destruição, da qual emerge o sentido imperativo da necessidade da responsabilidade para com a natureza, para com a fonte de vida da humanidade. Nesta concepção o homem deve preservar, cuidar, respeitar a natureza. Um apelo que surge como marca do discurso ambientalista, associado às dificuldades concretas da degradação ambiental, com a conseqüente perda da qualidade de vida da sociedade. Esta concepção, porém, não é de todo nova. Ela tem raízes antigas e, embora não tenha feito eco ao longo destes últimos dois mil anos de história, faz parte do ambíguo legado judaico-cristão.

As idéias que estão circulando na base das RSN dos grupos pesquisados em Gamela e Guadalupe são um tanto quanto ambíguas. Elas denotam o conflito atual entre o modelo de desenvolvimento trilhado pela sociedade humana e a escassez e degradação dos recursos da natureza para sustentação desse modelo. Uma encruzilhada onde "todos querem salvar a natureza se salvando, mas ninguém quer ir a pé”.

Nesta encruzilhada os conflitos anunciados parecem estar sugerindo a busca por uma negociação entre o velho e o novo. De um lado o velho: a natureza existe para suprir as necessidades humanas. Uma representação hegemônica que vem se configurando e re-configurando por séculos e séculos, na relação com tantas outras, que se diluíram no confronto com os interesses dos setores e classes sociais de cada época. Uma concepção totalmente arraigada à prática das várias classes sociais. Uma marca imprimida pelo modelo de sociedade, pelos modos através dos quais os GS e os seres humanos aprenderam a reproduzir a sua existência. Um espaço relacional que está sempre definindo e redefinindo uma nova configuração entre as representações da natureza e da humanidade.
Neste rumo, os estoques pesqueiros estão no limite de sua exaustão; parte da restinga e do manguezal em Gamela e Guadalupe foram consumidos pelo coqueiral que, atualmente junto com os dois primeiros, também está sendo devorado pelo loteamento e pela infra-estrutura viária. A expectativa, agora, é de mais uma onda de destruição, com as construções da rede hoteleira. Mas a representação hegemônica da natureza associada à ideologia do progresso, agora na fachada do turismo ecológico, reafirma a necessidade de utilização da natureza, na perspectiva do desenvolvimento sustentável.

O novo é representado por este anseio de responsabilidade para com a natureza, que como visto, não é tão novo quanto parece, pois é uma reedição de uma concepção que no passado não se constituiu em representação hegemônica por não se adequar aos interesses dominantes. A natureza está sendo destruída pelo homem, divinizado ou naturalizado, mas um homem descolado de seu contexto de sociedade, do modelo de desenvolvimento ao qual pertence.

A RS hegemônica da natureza parece viver um momento de crise, de conflito, de um lado a boa natureza, provedora, a ofertar seus recursos; de outro a natureza degradada por um homem mau, um destruidor, insaciável na utilização dos recursos naturais, ao qual se cobra à responsabilidade para com a primeira.

Uma representação de natureza positiva, a natureza edenizada, o paraíso ofertado por Deus, oposta à imagem do homem, que de sua generosidade usufrui. O ser humano, o outro que, no contexto das entrevistas, encarna o verdadeiro pecado original, é demonizado. Ele é mau, um destruidor da natureza. Um contexto de conflito; por um lado a oferta, a natureza para utilização, e por outro, a censura por sua utilização. Um espaço relacional mediado pela alteridade, que vai definindo o eu e o outro, o nós e a natureza, na construção e reconstrução das RS de natureza e de humanidade. Espaço de delineamento tanto das identidades individuais quanto grupais, de onde emergem as diferenças. 
Com relação a estas diferenças, o foco vai estar nas diferenciações grupais. Os resultados revelam que, a princípio, os grupos estudados compartilham as mesmas concepções na construção das RSN. Apesar desta orientação, emergem da comparação entre eles diferentes enfoques em função das diferenças de escolaridade, do nível sócio-econômico e do tipo de vínculo estabelecido com o lugar.

A partir da discussão exposta e tomando-se como referência o campo comum das RSN, considera-se que esta representação revelada é uma representação hegemônica; que deve apresentar diferentes focos de adequações em suas concepções, de acordo com o nível de degradação ambiental em que se insira a relação homem-natureza, grupo social-natureza e com os interesses sociais em jogo para a apropriação dos recursos da natureza na reprodução da vida, dos grupos evolvidos.

Ela está, entretanto, sendo questionada, o que se caracteriza na ambigüidade e no conflito apresentado. Um espaço de movimento e de negociação para uma transformação. Uma transformação que se apresenta ainda como muito "resistente” (Abric, 1998, p. 35). Os sinais nesta direção manifestam-se apenas na presença da orientação para o cuidado com a natureza. Esta é, no entanto, uma posição de que é preciso cuidar da natureza que se tem e que existe para atender às necessidades humanas. Uma posição menos antropocêntrica, no sentido de que a natureza não existe em função dos humanos, de que tem suas próprias leis, limites e potencialidades, indiferente aos interesses da sociedade humana, é uma posição que se apreende apenas na análise do contexto semântico do discurso e como modulação individual, associada à área de conhecimento, do participante que a apresentou:

Por ela possuir as suas próprias leis ela tem total importância. O planeta terra é o planeta vida. E para conservar essa vida é necessário consciência, preservação, não podemos ir de encontro à natureza. O homem não pode impor suas leis. Ela tem suas próprias leis. Dela extraímos tudo. Por isso que eu acho que é sinônimo de Deus. (Participante 209, biólogo)

Uma posição que revela a presença de conteúdos associados aos conhecimentos científicos que estão sendo desenvolvidos na área das ciências ambientais.

\section{Considerações finais}

O interesse deste trabalho foi verificar as possibilidades de utilização do estudo das RSN como instrumento para a gestão e EA. A idéia de partida é de que diferentes RS constroem diferentes RSN, em função do tipo de relação que estes grupos estabelecem com esse objeto a partir de seus conhecimentos, de suas práticas sociais e da forma como se apropriam dos recursos ofertados pela natureza, para reprodução de suas vidas. Representações, que não seriam de todo diferentes, devido às marcas comuns a elas imprimidas através de representações hegemônicas (ideologia dominante). Uma base comum marcaria as diferentes representações e práticas sociais; valores, interesses, sentidos e significados, definindo e redefinindo as interações entre GS diversos, no curso das construções do ambiente.
A partir deste norte, o estudo foi direcionado para verificar as RS de moradores, veranistas e turistas que interagem nas praias de Gamela e Guadalupe, na APA de Guadalupe, com a finalidade de fundamentar a utilização deste referencial teórico e prático como instrumento para a gestão e EA.

As representações analisadas apresentaram tanto elementos de diferenciação, como de identidade entre si. Os elementos de identidade emergiram da relação entre os diferentes elementos estruturadores das representações e uma mesma base ideológica, que destaca, como comum aos grupos, o sentido de natureza enquanto fonte de vida para o ser usada pelo homem. As peculiaridades grupais são estruturadas a partir de diferentes elementos, aos quais vão sendo atribuídos também diferentes sentidos e significados que definem identidades, posições, conhecimentos, valores, interesses, motivações e práticas sociais subjacentes às inserções sociais de cada grupo. A natureza foi sendo traduzida, então, como alimentação e trabalho, como paz, beleza e lazer ou até como cuidado e preservação.

A análise das peculiaridades grupais revelou, também, que a idade dos participantes não parece interferir nos resultados obtidos. Por outro lado, o tipo de vínculo e de relação que estes participantes tinham com o lugar é uma variável que interfere no conteúdo das RSN. Vale ressaltar, entretanto, que o tipo de vínculo também pode estar relacionado a outras variáveis como nível sócio econômico e escolaridade, uma vez que os moradores tinham uma baixa escolaridade e um nível sócio econômico inferior aos turistas e veranistas.

O grande traço de identidade entre os grupos está apoiado nos elementos da ancoragem que, marcados pela ideologia dominante, justificam as atuais práticas sociais dos diferentes grupos pesquisados. O estudo das RS do objeto natureza está sempre na dimensão relacional de onde emerge não apenas o objeto natureza, mas, a relação, a categoria analítica humanidade, sociedade humana-natureza, encontro do eu e do outro, do nós e da natureza na construção e reconstrução de novas configurações desta relação. Um encontro já revisitado por muitos (Arruda, 1998; Brown, 1991; Passmore, 1995; Thomas, 1989) em diferentes épocas e lugares. Nesta ótica, resgata-se a posição de Passmore (1995, p. 98) quanto à importância do pensamento racional e da ciência para apropriação do objeto natureza, nesta dimensão relacional. Posição que se coaduna com a perspectiva científica de possibilidade de transformação das RSN guiada por um processo educativo que tenha por base uma orientação científica do objeto natureza e do processo do conhecer.

Como se esperava, esta abordagem produziu conhecimentos sobre as RSN dos grupos pesquisados que podem orientar a organização de conteúdos e práticas para uma ação de EA. A direção é da superação de idéias, que terminam por fortalecer valores, atitudes e práticas sociais que contribuem para a degradação ambiental, por idéias que favoreçam o seu oposto e a organização dos grupos para a defesa da natureza local. Nesta direção é preciso a preocupação, por um lado, com conhecimentos científicos, como leis mais gerais que extrapolam características locais, mas e principalmente, por outro, com as peculiaridades das condi- 
ções dos ecossistemas e recursos naturais locais, também na perspectiva da ciência.

Desta forma, contrapondo-se às idéias de natureza como algo que existe para servir aos seres humanos (idéia identificada na ancoragem), deve-se considerar para uma abordagem da EA na área três condições reconhecidas por Passmore (1995) como importantes para qualquer filosofia da natureza que tenha a ciência como referência. São elas: (a) que a natureza tem suas próprias leis, ritmos e cursos, indiferentes aos interesses dos seres humanos; (b) que a natureza enquanto sistema complexo pressupõe um sistema de interações em cadeia que acena para a impossibilidade de sua completa dominação, e de, portanto, a necessidade de se impor limites e cautela às ações sobre ela; e (c) para entender a natureza, para a descoberta de suas leis gerais, o modelo da física freqüentemente tem importância limitada. Para a compreensão das estruturas biológicas ou sociais, o que mais importa é o conhecimento detalhado de circunstâncias muito específicas.

Outras reflexões, agora no contexto de obtenção dos resultados, abrem também espaço para se pensar sobre os limites e dificuldades existentes para aplicação deste referencial teórico à ação teórica e prática da EA. Inicialmente, aparece como dificuldade a pouca produção de trabalhos na área - RS/EA - que alimentem o espaço de crítica e reflexão, gerando novos avanços e contribuições. Depois, a dificuldade da identificação de metodologias de pesquisa e análise testadas e adaptadas aos interesses e objetivos da ação da EA.

Nessa direção, os resultados contribuem para uma reflexão acerca da metodologia utilizada para coleta e análise dos dados por este estudo e uma proposta de sua adaptação, sempre com o objetivo de melhorar a compreensão das relações entre RSN e prática social. Uma proposta que busca avançar no aprimoramento da utilização das abordagens metodológicas orientadas pela teoria das RS para as ações em EA, que pode até mesmo ser orientada para outros objetos.

Este estudo esteve respaldado, por um lado, na posição de Moscovici (2000), que destaca a complexidade e elasticidade da teoria das RS, como sinônimo de fluidez e de possibilidades de adaptação à diversidade de problemas a resolver e de novos fenômenos a descrever e explicar. Uma elasticidade que se estende também aos enfoques metodológicos utilizados. As metodologias e técnicas de pesquisa não devem ser um fetiche. É necessário buscarem-se possibilidades alternativas múltiplas, poder contar com análises quantitativas, sem eliminar a riqueza das aproximações qualitativas e participantes.

Por outro lado, está a importância do entendimento da dimensão teórica e prática das interações sociedade-natureza para a ação da EA. Um espaço de preocupação, que em se tratando do senso comum é foco de interesse também da TRS. Neste sentido, a relação entre a RSN e a efetiva prática social dos grupos com a natureza precisa ser mais bem compreendida, para que estratégias e conteúdos educativos adequados possam ser efetivamente identificados e aplicados.

A proposta é direcionar o estudo das RS para a relação entre os dois focos: O que é a natureza? E, quais as práticas sociais dos participantes para com a natureza? Uma orientação perfeitamente adaptável aos recursos de coleta e análise de dados utilizados.

Além desta primeira reflexão, outro ponto merece especial atenção para aplicação desta abordagem. Trata-se dos cuidados que devem ser tomados pelo pesquisador para evitar a dimensão subjetiva de sua análise e, ao mesmo tempo, buscar enxergar para além do que o participante pode estar querendo filtrar nas suas informações, com base em seus valores e interesses, ou até com base no que ele está supondo que se quer ouvir. Esta é uma referência que está diretamente relacionada aos procedimentos e referenciais metodológicos a serem utilizados. Uma decisão a ser tomada com base na adequação entre as condições e objetivos da pesquisa, as possibilidades metodológicas disponíveis e as características dos participantes a serem pesquisados. Possibilidades, que de acordo com as orientações teóricas e práticas das abordagens em RS se abrem tanto para os métodos quantitativos, como qualitativos, e na melhor das hipóteses, para abordagens pluri-metodológicas que possam garantir maior segurança dos resultados.

Outros pontos, que se coadunam com os princípios norteadores da EA foram reafirmados neste contato teórico e empírico com a abordagem das RS. Eles reforçam a importância desta abordagem na ação da EA e alguns deles merecem destaque: a ótica da complexidade e plasticidade; a orientação interdisciplinar e intersubjetiva; a perspectiva relacional individual/social; a constatação da existência do espaço relacional dialógico entre o senso comum e o conhecimento científico e o caráter dinâmico das RS que se abre à possibilidade de mudanças na ação social.

Todas as constatações anteriores confirmam a fertilidade deste espaço de produção de conhecimentos. Orientação imprescindível a uma ação de educação e GA coerente com os princípios da interdisciplinaridade, respeito à diversidade cultural e adequação à realidade e aos conteúdos e conhecimentos das comunidades e públicos a serem envolvidos em uma ação educativa que tenha como perspectiva estimular o processo de construção de um pensamento crítico acerca da relação sociedade humana-natureza.

Os conhecimentos produzidos trazem implicações para duas dimensões de aplicação: sua utilização na ação educativa e gestora local; e a viabilidade de uso das RSN como instrumento de gestão e EA, coerente com princípios e orientações teóricas e metodológicas também presentes nas ciências ambientais. Novos estudos poderiam se desenvolver ao longo de perspectivas dessas duas dimensões.

Na primeira, duas perspectivas se revelam: (a) a realização de uma ação educativa, organizada a partir dos dados obtidos no presente estudo, para os grupos já pesquisados, um espaço de consolidação da aplicabilidade deste 
referencial teórico e metodológico; (b) a necessidade de pesquisa para o conhecimento das RSN dos outros GS que interagem na APA de Guadalupe, com a finalidade de realizar uma ação educativa e gestora em toda a unidade de conservação, mais crítica e comprometida com um processo de apropriação e reconstrução do "real", integrando os diferentes valores, sentidos e interesses de todos os GS na busca de um agir e conhecer a natureza, mais coerente com a realidade dos problemas locais do ambiente e a gravidade da crise ambiental global.

A outra dimensão extrapolaria os limites da APA de Guadalupe. O objetivo seria ter a relação humanidade-natureza, nas mais diferenciadas situações de encontro, como categoria analítica para o estudo das RSN, constituindo-se num espaço crítico para conhecer e reconhecer a natureza nessa perspectiva relacional, condição que se apresenta imprescindível à ação crítica, teórica e prática, da gestão e EA. Nessa direção, este trabalho teve a pretensão de contribuir para o aprofundamento da discussão acerca da utilização da TRS como um dos referenciais teóricos e instrumentos metodológicos para o conhecimento das RSN que se constitui no espaço relacional sociedade humana-natureza, no percurso da construção do ambiente e da realidade da questão ambiental.

\section{Referências}

Abric, J. C. (1998). A abordagem estrutural das representações sociais. In A. S. P. Moreira \& D. C. Oliveira (Org.), Estudos interdisciplinares de representação social (pp. 27-38). Goiânia: AB.

Alves-Mazzotti, A. J. (1996). Representações sociais: aspectos teóricos e aplicações à educação. Em Aberto, 14(61), 60-76.

Arruda, A. (1998). O ambiente natural e seus habitantes no imaginário brasileiro. In A. Arruda (Org.), Representando a alteridade (pp. 17-46). Petrópolis: Vozes.

Brown, P. (1991). Antiguidade tardia. In G. Duby \& Ph. Àries \& (Orgs.), História da vida privada (vol. 1, pp. 17-46). São Paulo: Companhia das Letras.

Companhia Pernambucana do Meio Ambiente /CPRH. (1998). Diagnóstico sócio-ambiental da APA de Guadalupe. Recife: Autor.

Correa, R. L. (2001). Espaço, um conceito-chave da Geografia. In I. E. Castro, P. C. C. Gomes, \& R. L. Correa (Org.), Geografia: conceitos e temas (3 $3^{\mathrm{a}}$ ed., pp. 15-45). Rio de Janeiro: Bertrand Brasil.

Doise, W. (2000). Da psicologia social à psicologia societal. Conferência proferida por ocasião da aula inaugural no Instituto de Psicologia, Universidade de Brasília.

Moscovici, S. (1978). A representação social da psicanálise. Rio de Janeiro: Zahar. Moscovici, S. (2000). Prefácio. In P. Guareschi \& S. Jovchelovitch (Orgs.), Textos em representações sociais ( $6^{\mathrm{a}}$ ed., pp. 7-16). Petrópolis: Vozes.

Passmore, J. (1995). Atitudes frente a natureza. Revista de Geografia (Recife/ UFPE), 11(2), 91-102.

Thomas, K. (1989). O homem e o mundo natural. São Paulo: Companhia das Letras.

1 "natureza em um de seus sentidos mais restritos: apenas incluindo aquilo que deixando de lado o sobre-natural, designa o que não é humano” (Passmore, 1995, p. 91).

2 "A definição dos grupos provêm de um feixe de pressupostos que confere peso diferencial a certo número de critérios. Ex: critérios socioeconômicos, critérios profissionais”. Ele introduz também, elementos de controle, por exemplo: separar em grupos diferentes pescadores com escolaridade e sem escolaridade (Moscovici, 1978, p. 74).

${ }^{3}$ É calculado tomando-se como referência as associações das palavras em diferentes classes a partir da relação entre a expectativa de emergência e a emergência de fato dessas palavras em cada classe (cálculo do $\chi^{2}$ ).

4 “O lugar possui um 'espírito', uma 'personalidade’ um 'sentido de lugar’ que se manifesta pela apreciação visual ou estética e pelos sentidos a partir de uma longa vivência.” (Correa, 2001, p. 31)

Lúcia Maria Alves e Silva, mestre em Gestão e Políticas Ambientais pela Universidade Federal de Pernambuco, é doutoranda no Programa de Educação da Universidade Federal de Pernambuco. Endereço para correspondência: Rua Treze de Maio, 271, Varadouro; Olinda, PE; CEP 53020-170. Tel: (81) 3439-3004 ou 2123-1882. Fax: (81) 2123-1921. E-mail: luciamaria@cprh.pe.gov.br

Edvânia Torres Aguiar Gomes, doutora em Geografia pela Universidade de São Paulo, é professora no mestrado de Gestão e Políticas Ambientais da Universidade Federal de Pernambuco. E-mail: torres@npd.ufpe.br Maria de Fátima de Souza Santos, doutora em Psicologia pela Universidade de Toulouse II, França, é professora no Programa de Pós-Graduação em Serviço Social e no Departamento de Psicologia da Universidade Federal de Pernambuco.E-mail: mfsantos@ufpe.br 